\title{
UTERINE INVERSION DURING CESAREAN SECTION: A RARE CASE
}

\author{
Nemagouda Aruna S ${ }^{1}$, Shirgur Shobha S², Gobbur Vijaylakshmi R³, Patil Neelamma ${ }^{4}$
}

\section{HOW TO CITE THIS ARTICLE:}

Nemagouda Aruna S, Shirgur Shobha S, Gobbur Vijaylakshmi R, Patil Neelamma. "Uterine Inversion during Cesarean Section: A Rare Case". Journal of Evolution of Medical and Dental Sciences 2014; Vol. 3, Issue 21, May 26; Page: 5771-5774, DOI: $10.14260 /$ jemds/2014/2662

INTRODUCTION: Inversion of uterus even though very rare during caesarean section, it's a potentially life threatening emergency complication. If reposition of the uterus is not done immediately then following excessive blood loss can lead to hemodynamic instability, shock which need proper resuscitation. Uterine inversion during caesarean is noted very rarely. But the incidence noted is much lower following vaginal delivery compared to caesarean section which is around one in 1860 cases according to study done by Basket TF. ${ }^{1}$

Here, we present a case of uterine inversion during caesarean section. Wherein we successfully reverted back but could not salvage the uterus due to uncontrolled bleeding from the placental bed.

CASE PRESENTATION: A 23 year old healthy G3P2L2 with FTP with previous 2 caesarean section presented to labor room with labor pains 3 hours prior to admission. Her first caesarean section was done for twin pregnancy $2 \frac{1}{2}$ years back and $2^{\text {nd }}$ for transverse lie $1 \frac{1}{2}$ years back. She did not have any other high risk factors.

Patients history: Obstetric history - previous 2 LSCS otherwise it's uneventful. Personal/ past and family history unremarkable.

On Examination: Her general condition was good, no pallor. Pulse rate - 82bpm; Blood pressure - 110/70mmHg. Cardiovascular system \& Respiratory system - no abnormality detected. Per Abdomen examination - uterus term size, acting 2-3 contractions/ 25-30 "/ 10 min, head lower down and $4 / 5^{\text {th }}$ palpable, fetal heart sound was present and regular, no scar tenderness. Per Vaginal examination - Cervix $20 \%$ effaced, $1 \mathrm{~cm}$ dilated, membranes present, vertex -3 station.

Investigations were within normal limits. In view of previous 2 LSCS, patient was shifted for emergency LSCS under spinal anesthesia.

Delivery of the fetus was uneventful. After the baby was born, 10 I.U of oxytocin was given intramuscularly intraoperatively. Uterine contraction was noted and slow control cord traction was applied to remove the placenta. With little traction, complete uterine inversion occurred through the uterine incision with placenta firmly attached to the uterine fundus (Figure 1).

The inverted uterus with placenta was exteriorized and slowly the placenta was removed which was slightly adherent to uterus. Oxytocin infusion was stopped and slowly uterus reposition was done by reverting the last inverted part back first and was successfully reverted back. 20 I.U of oxytocin infusion started in $500 \mathrm{ml}$ of ringer lactate to maintain the uterine contractions, methylergometrine, PGE1 and PGF2 were also given. There were no significant changes seen in the patient's hemodynamic state but the bleeding from the placental was continuous and could not be controlled even with multiple sutures at the placental bed.

So, keeping the multiparty of the patient and acute blood loss of around $2000 \mathrm{ml}$ in mind, decision of obstetric hysterectomy was taken (Figure 2). Patient underwent subtotal hysterectomy. 


\section{CASE REPORT}

The intra operative and post- operative period was uneventful. Patient was given 1 pint whole blood transfusion post operatively. Patient was discharged on $7^{\text {th }}$ post-operative day.

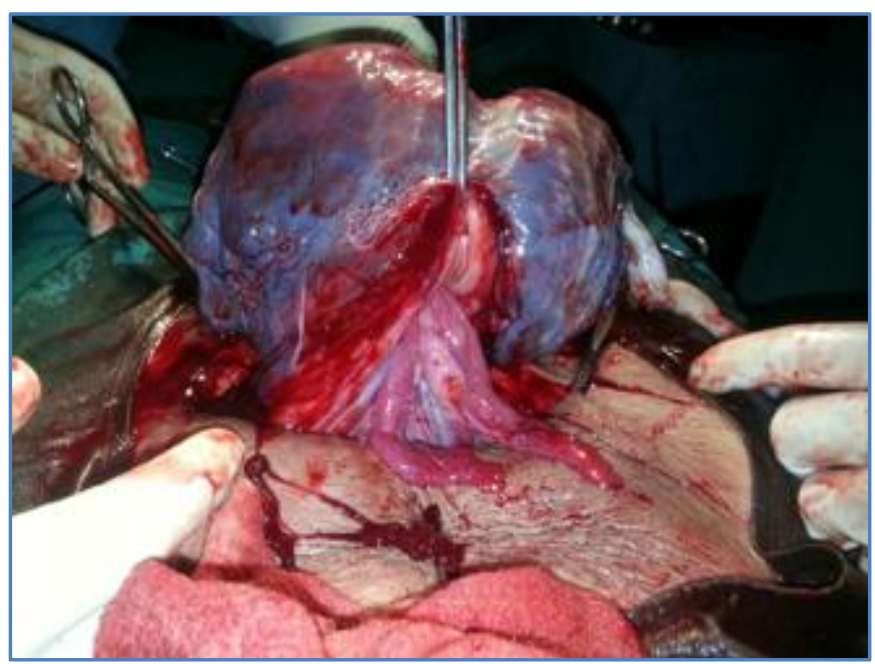

Figure 1: Showing inverted uterus through uterine incision with adherent placenta

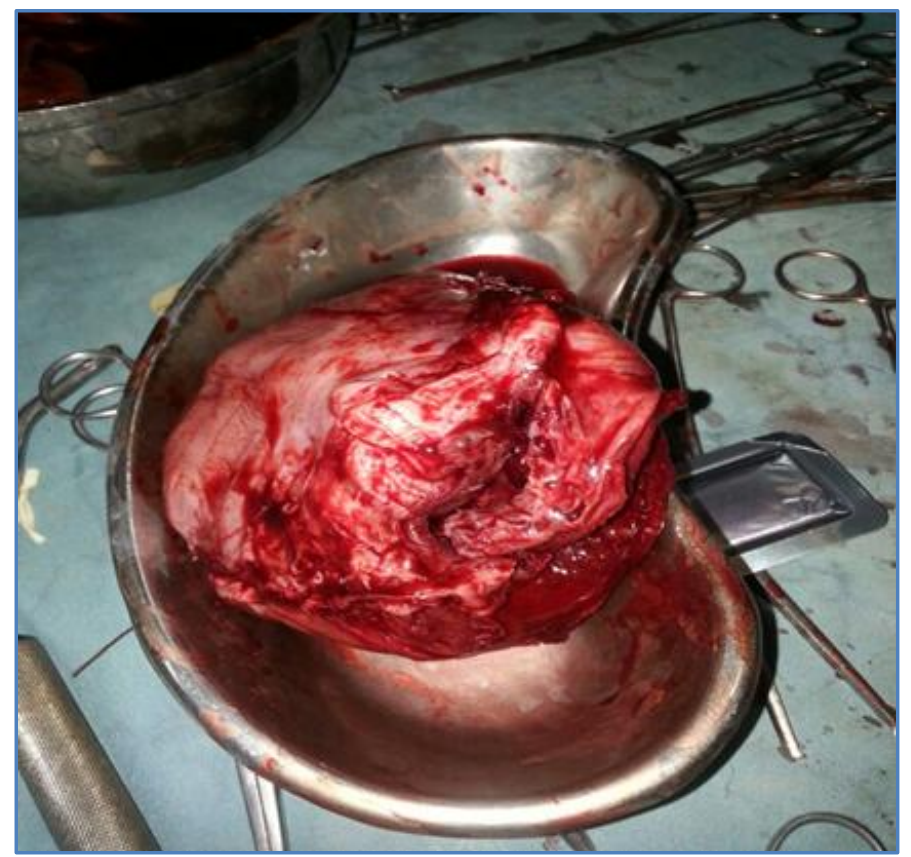

Figure 2: showing uterine specimen post hysterectomy

DISCUSSION: Uterine inversion during caesarean section is supposed to be a rare life treating emergency complication. But still we believe that, it's a very rare complication which occurs during caesarean. In the literature unique case of cervical inversion ${ }^{2}$ and uterine torsion of inverted uterus $^{3}$ are noted during caesarean section. 
The exact etiology of this complication still remains unclear. Some contributing factors may be like: Fundal insertion of the placenta, ${ }^{4}$ inherent weakness of the uterine musculature, ${ }^{4,5}$ administration of oxytocin, in particular when given as bolus,5,6 traction of the cord with the placenta, either partially or completely attached to the uterus [adherent placenta].6-8

It's a serious \& life threating complication. The complicating features are hemorrhage \& shock. The blood loss depends upon the time taken from the inversion of the uterus and its reversal and the more increase in the time interval, will lead to serious hemodynamic instability.5, 9, 10

Neurogenic complications like hypotension and shock may be due to traction on infundibulopelvic ligament or secondary to peritoneal or broad ligament stretching. ${ }^{6}$

As the patient will be under anesthetic effect, the neurogenic part remains eliminated, making blood loss the main reason for patients instability. However identifying the inversion and reverting it remains the ideal management in these cases as delay in that may lead to fatal complications. ${ }^{4,5}$

One study has said that administration of sevoflurane may help in rapid repositioning of the inverted uterus by relaxing the uterus. But the effect is dose dependent on human myometrium. ${ }^{11}$

In our case there was complete inversion of uterus following control cord traction. The fundal insertion of placenta, multiparity leading to inherent uterine muscle weakness and cord traction, even though it was controlled may be the contributing factions in our case. It was diagnosed early and repositioning was done promptly and was successful. But, the patient had to undergo obstetric hysterectomy due to continuous placental bed bleeding.

CONCLUSION: Uterine inversion during caesarean section is often a rare, unexpected and a serious life threating complication. Timely diagnosing and reversion of this uterine inversion without delaying much is the principal of management in this life threatening emergency obstetric complication. All the obstetricians should be aware of this complication.

\section{REFERENCES:}

1. Basket TF. Acute uterine inversion: a review of 40 cases. J Obstet Gynaecol Can 2002, 24(12):953-956.

2. Sivasurija M, Herath HP. Inversion of cervix uteri at caesarean section. Br Med J 197 6, I (6012):746-747.

3. Cindr J, Cepicksy P. torsion of the uterus due to uterine inversion during caesarean section. Cesk Gynekol 1989, 54(9):690-692.

4. Banerjee N, Deka D, Roy KK, Takkar D. Inversion of the uterus during caesarean section. Eur J Obstet Gynecol Repord Biol 2000, 91:75-77.

5. Rudloff U, Joels LA, Marshall N. Inversion of uterus at caesarean section. Arch Gynecol Obstet 2004, 269: 224-226.

6. Emmott RS, Benette A. Acute inversion of uterus at caesarean section. Anaesthesia 1988, 43: 118-120.

7. Kriplani A, Relan S, Roy K, Mittal S, Buckshes K. Complete inversion of uterus during caesarean section - a case report. Aust N Z J Obstet Gynecol 1996, 36: 17-19.

8. Terp MR, Rasmussen KL. Uterine inversion during caesarean section. Acta Obstet Gynecol Scand 1998, 77: 788-789. 


\section{CASE REPORT}

9. Studzinski Z, Branicka D. Acute complete uterine inversion - case report. Ginekol Pol 2001, 72(11): 881-884.

10. Khalil A, Raafat A, Kalleja Agius J, Bell R, O’Brien P. Cardiac arrest associated with uterine inversion during caesarean section. J Obstet Gynaecol 2006, 26(7): 696-697.

11. Turner RJ, Lambrust M, Holmes C, Katz SG, Downs CS, Collins DW, Gatt SP. The effect of Sevoflurane on isolated Gravid Human Myometrium. Anasth Intensive Care 2002, 30: 591-596.

\section{AUTHORS:}

1. Nemagouda Aruna S.

2. Shirgur Shobha S.

3. Gobbur Vijaylakshmi R.

4. Patil Neelamma

\section{PARTICULARS OF CONTRIBUTORS:}

1. Assistant Professor, Department Obstetrics and Gynaecology, Shri B. M. Patil Medical College Hospital and Research Center.

2. Assistant Professor, Department Obstetrics and Gynaecology, Shri B. M. Patil Medical College Hospital and Research Center.

3. Professor, Department Obstetrics and Gynaecology, Shri B. M. Patil Medical College Hospital and Research Center.
4. Associate Professor, Department Obstetrics and Gynaecology, Shri B. M. Patil Medical College Hospital and Research Center.

\section{NAME ADDRESS EMAIL ID OF THE CORRESPONDING AUTHOR:}

Dr. Nemagouda Aruna S,

C/o. Dr. M. S. Biradar,

Matoshree, Basaweshwar Housing Colony, Opposite Shri B. M. Patil College,

Ashram Road, Bijapur-586103.

Email: aruna.biradar@yahoo.com

Date of Submission: 08/05/2014.

Date of Peer Review: 09/05/2014.

Date of Acceptance: 17/05/2014.

Date of Publishing: 24/05/2014. 